\title{
The potential of the marine bivalve mollusc Glossus humanus (L.) as a sclerochronological archive
}

\author{
David J Reynolds, ${ }^{1,6}$ Chris A Richardson,' James D Scourse,' Paul G \\ Butler, ' Alan D Wanamaker Jr, ${ }^{2}$ lain Ridgway, ${ }^{3}$ Martin DJ Sayer ${ }^{4}$ and \\ Pauline Gulliver ${ }^{5}$
}

\begin{abstract}
In order to assess its potential as a sclerochronological archive, we present statistical and geochemical analyses of internal growth increment series in shells of the heart cockle Glossus humanus (L.), a large marine bivalve. The investigated samples were collected from Loch Sunart and the Sound of Mull, Scotland, United Kingdom. High-resolution stable isotope $\left(\delta^{18} \mathrm{O}\right)$ analyses and radiocarbon $\left({ }^{14} \mathrm{C}\right)$ determinations indicated that $\mathrm{G}$. humanus forms annual growth lines. Examination of the growth increment series revealed that the maximum longevity of $G$. humanus in this region was 78 years. Radiocarbon dating and crossmatching techniques, derived from dendrochronology, were used to provide an estimation of the temporal distribution of the fossil $G$. humanus. Of the shells that contained $>25$ growth increments, seven were found to statistically crossmatch, including shells from two distinct sites $15 \mathrm{~km}$ apart. The calibrated ${ }^{14} \mathrm{C}$ determinations independently confirmed the crossmatching of three $\mathrm{G}$. humanus shells from the Sound of Mull with a separately constructed Glycymeris glycymeris chronology and a further three G. humanus shells from site 3, in the main basin of Loch Sunart, but indicate a significant difference (site I) in the antiquity of the two $G$. humanus populations. Radiocarbon dating indicated that, despite their fragile nature, $G$. humanus shells remain preserved in near original condition for at least 700 years. Given the small amount of available shell material, it is unlikely that $G$. humanus will become a key species for the construction of long absolutely dated sclerochronologies. However, these data do indicate that the annually resolved $G$. humanus growth series could be used to supplement series from other long-lived bivalves and facilitate the construction of a robust multispecies sclerochronology spanning the last 1000 years.
\end{abstract}

\section{Keywords}

annual growth increments, Glossus humanus, Glycymeris glycymeris, heart cockle, Loch Sunart, oxygen isotopes, sclerochronology

Received 24 February 20I2; revised manuscript accepted 26 July 2013

\section{Introduction}

It has been recognized since the 1970s that bivalve molluscs such as Arctica islandica, Modiolus modiolus, Mercenaria mercenaria and Spisula solidissima (Richardson, 2001) contain a continuous record of their ontogeny in the form of internal growth patterns, that is, growth increments delimited by growth lines (Rhoads and Lutz, 1980; Richardson, 2001; Rosenberg and Runcorn, 1975). The growth line records derived from live- and dead-collected long-lived bivalves, such as A. islandica (L.), form the foundation of sclerochronologies, which provide robust temporal frameworks for high-resolution palaeoenvironmental research (Butler et al., 2010; Schöne et al., 2005; Scourse et al., 2006; Wanamaker et al., 2008a). Growth increment series and shell geochemistry have hitherto been used as palaeoenvironmental proxies, reconstructing environmental parameters such as sea surface temperature (SST; Jones, 1981; Reynolds et al., 2013; Strom et al., 2004), air temperature (Schöne et al., 2004), productivity dynamics (Witbaard et al., 2003), dominant modes of atmospheric forcing (Schöne et al., 2003) and ocean dynamics (Ambrose et al., 2006; Wanamaker et al., 2008b, 2012).

The bivalve A. islandica has attracted considerable and detailed attention within the sclerochronological community due to its great longevity (>500 years; Butler et al., 2013), growth increments of proven annual periodicity (Jones, 1980; Thompson et al., 1980; Weidman et al., 1994) and demonstrated synchronicity of growth between coeval individuals within and between populations (Butler et al., 2010; Marchitto et al., 2000). Hitherto, the majority of published sclerochronologies have utilized the growth increment series in A. islandica. However, the distribution of live and dead (fossil) shell valves of A. islandica is not homogenous in time and space, being constrained by water depth, seawater temperature and sediment type (Dahlgren et al., 2000). There are therefore areas of significant hydrographic and oceanographic interest that cannot be studied using A. islandica. Given this constraint, it is therefore desirable to investigate the potential of other long-lived species as sclerochronological archives in order to broaden the spatial coverage of marine environmental reconstructions.

\footnotetext{
'Bangor University, UK

${ }^{2}$ lowa State University, USA

${ }^{3}$ Max Planck Institute for Demographic Research (MPIDR), Germany

${ }^{4}$ Scottish Association for Marine Science, UK

${ }^{5}$ SUERC, UK

${ }^{6}$ Cardiff University, UK
}

\section{Corresponding author:}

David J Reynolds, School of Earth and Ocean Science, Cardiff University, Main Building, Park Place, Cardiff CFI0 3AT, UK.

Email: ReynoldsD3@cardiff.ac.uk 

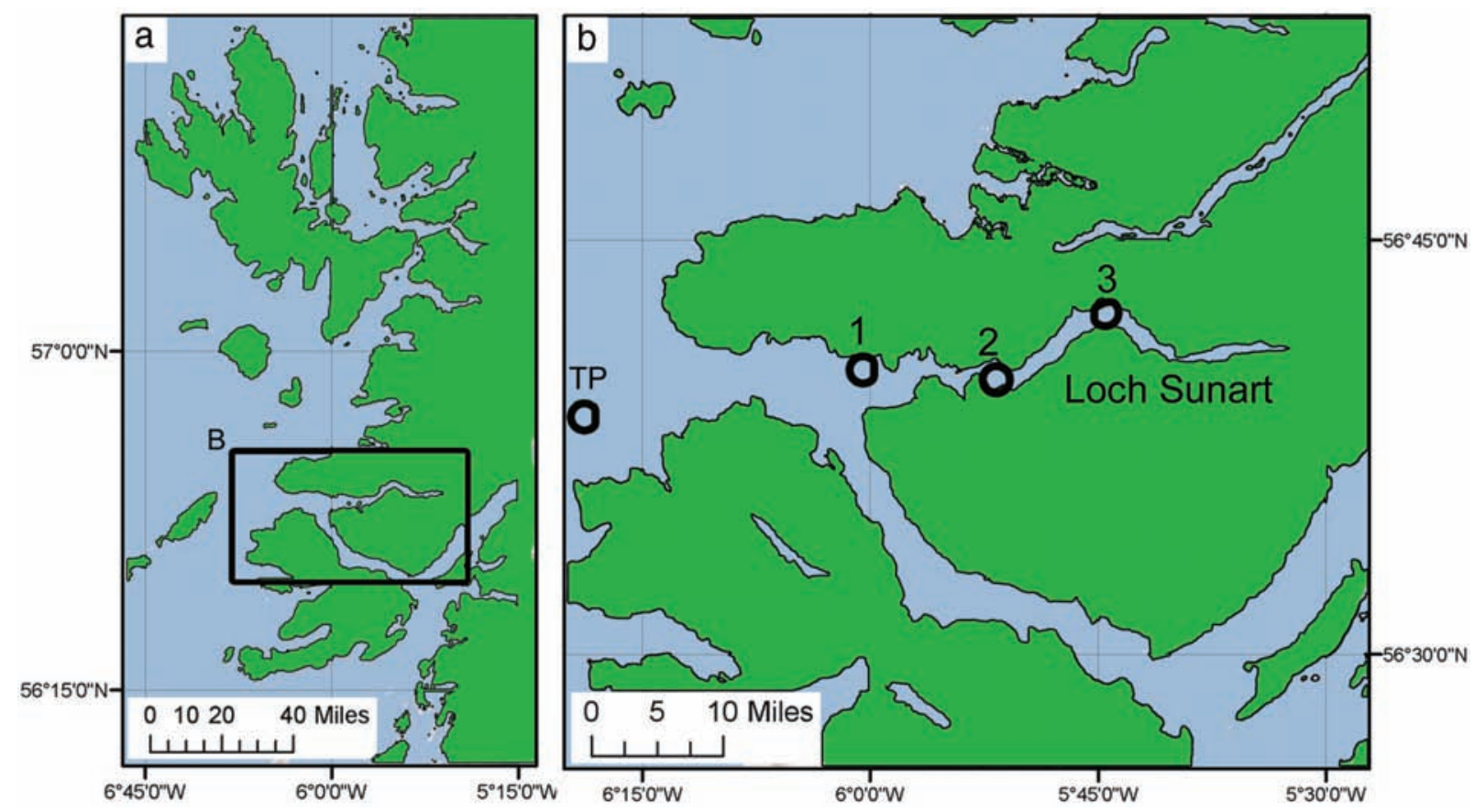

Figure I. Map showing the location of Loch Sunart and The Tire Passage on the NW Coast of Scotland (a). (b) Map showing the position of the three Glossus humanus sample collection sites in Loch Sunart and the Glycymeris glycymeris sclerochronology from the Tiree Passage (TP). Site $I$ is situated in the Sound of Mull, whilst sites 2 and 3 are located in the main basin of Loch Sunart.

The heart cockle, Glossus humanus (Linné, 1758), the sole extant species of the family Glossidae, is a large $(110 \mathrm{~mm}$; Owen, 1953) infaunal bivalve mollusc that has inhabited the fine mud substrata of the coastal shelf seas of Europe and the Mediterranean, from $32^{\circ} \mathrm{N}$ to $64^{\circ} \mathrm{N}$ (Nicol, 1951; Owen, 1953) since at least the middle Miocene (16-11.5 Ma; Balson, 1990). Modern occurrences of live specimens in the coastal shelf seas of Scotland are relatively scarce, but $G$. humanus appears to be more common in the fossil record. G. humanus is of particular interest because its geographical distribution complements that of $A$. islandica, as it inhabits the cohesive muds, characteristic of low-energy basins, which are thought to be too soft for the generally heavier $A$. islandica (Owen, 1953), and therefore has the potential to extend the range of environments in which sclerochronological investigations could be applied.

Shell material examined in this study was collected from three localities in northwest Scotland (Figure 1a). Water masses at this latitude on the Hebridean shelf are derived from the Scottish Coastal Current (SCC) and the North Atlantic Slope Current (NASC; Inall et al., 2009). The SCC, formed in the North Channel between Scotland and Northern Ireland, is a mixture of Irish Sea and Celtic Sea waters. SCC water is less saline than NASC water because it incorporates influxes of fresh water from rivers and sea lochs as it flows north, unlike the NASC which flows mainly along the continental margin, with occasional protrusions onto the shelf (Inall et al., 2009). Loch Sunart exhibits typical fjordic hydrographic characteristics, with a brackish surface layer with salinity increasing with depth (Cage and Austin, 2010). Within the main basin, the tidal regime is semi-diurnal with seawater influx largely unrestricted by the outermost sill (c. $35 \mathrm{~m}$ water depth)

This study aims to address the key issues in the development of any novel sclerochronological palaeoenvironmental archive (1) to assess the optimal method of imaging the internal banding so that the entire ontogenetic growth record can be examined, (2) to determine which calcium carbonate polymorph(s) are present in the shell, (3) to assess the periodicity of growth line formation and (4) to examine the temporal distribution of $G$. humanus shells
Table I. Latitudes, longitudes and water depths of the three stations from where the Glossus humanus shell material was collected.

\begin{tabular}{llll}
\hline Site & Latitude & Longitude & Water depth $(\mathrm{m})$ \\
\hline 1 & $56^{\circ} 40.50 \mathrm{~N}$ & $6^{\circ} 00.25 \mathrm{~W}$ & $35-45$ \\
2 & $56^{\circ} 42.00 \mathrm{~N}$ & $05^{\circ} 45.50 \mathrm{~W}$ & 60 \\
3 & $56^{\circ} 40.00 \mathrm{~N}$ & $05^{\circ} 52.00 \mathrm{~W}$ & 55 \\
\hline
\end{tabular}

by means of cross dating and accelerator mass spectrometry (AMS) ${ }^{14} \mathrm{C}$ dating.

\section{Materials and methods}

\section{Sample collection and preparation}

Shells used in this study were predominantly collected by mechanical dredge deployed by the research vessel (RV) Prince Madog at three sites in Loch Sunart and the Sound of Mull, NW Scotland (see Figure 1 and Table 1) in September 2006. Additional shell material was subsequently collected from the same sites by the UK Natural Environment Research Council (NERC) National Facility for Scientific Diving (NFSD).

Single and articulated dead G. humanus valves were collected by mechanical dredge from a single site on the seaward side of the outer sill in the Sound of Mull (site 1) and two sites in the main basin of Loch Sunart (sites 2 and 3; Table 1). A single live $G$. humanus was collected by the NFSD team from site 3 . The shells were collected from fine mud substrata at water depths from 35 to $65 \mathrm{~m}$. Shell morphometrics (shell length, shell height, max height, width and mass) as well as shell condition (periostracum preservation, ligament preservation, margin preservation and bioerosion) were measured and recorded. Shell morphometrics have been shown to provide a good estimate of longevity within populations of $A$. islandica located in adjacent sea lochs (Stott et al., 2010) as well as in populations off 


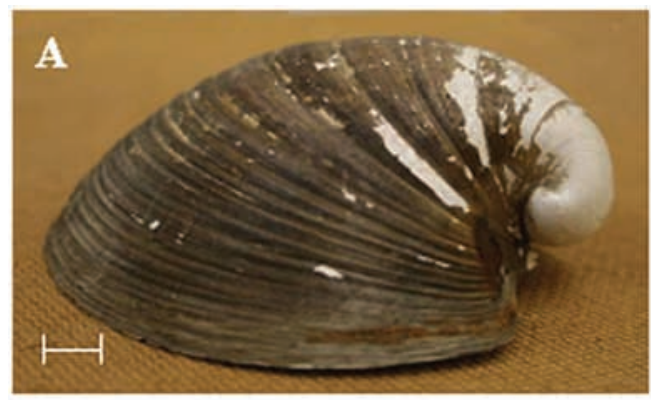

B
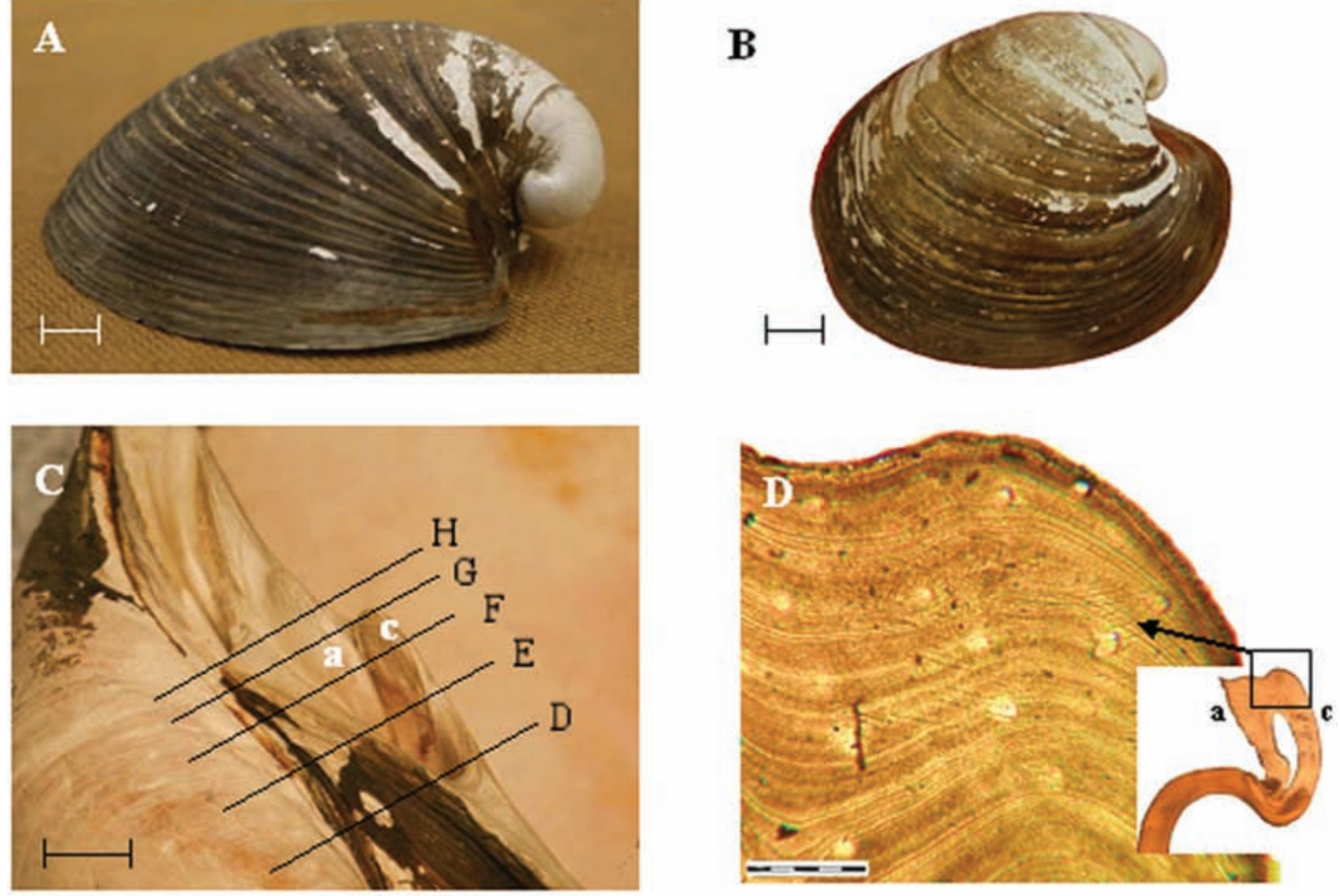

$\mathbf{E}$

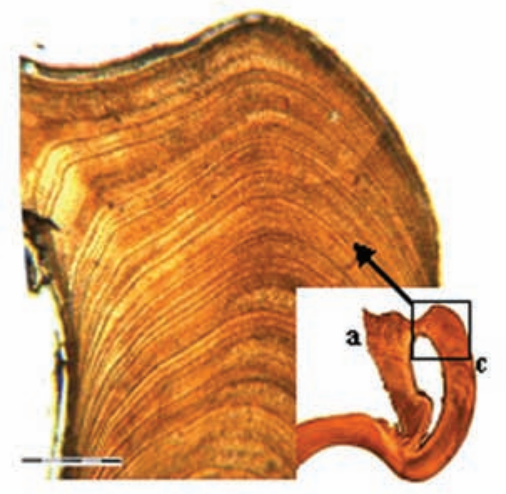

$\mathbf{F}$

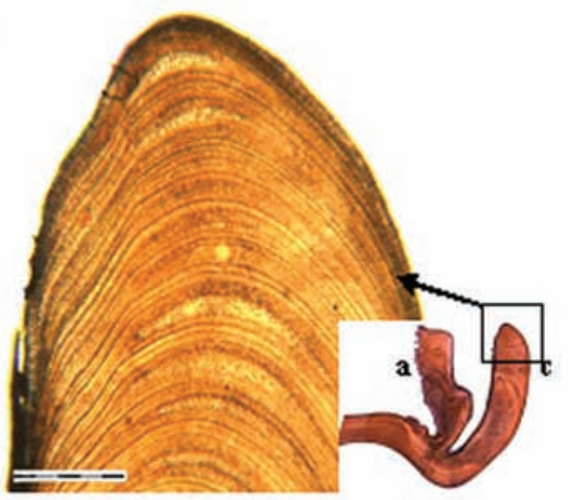

G
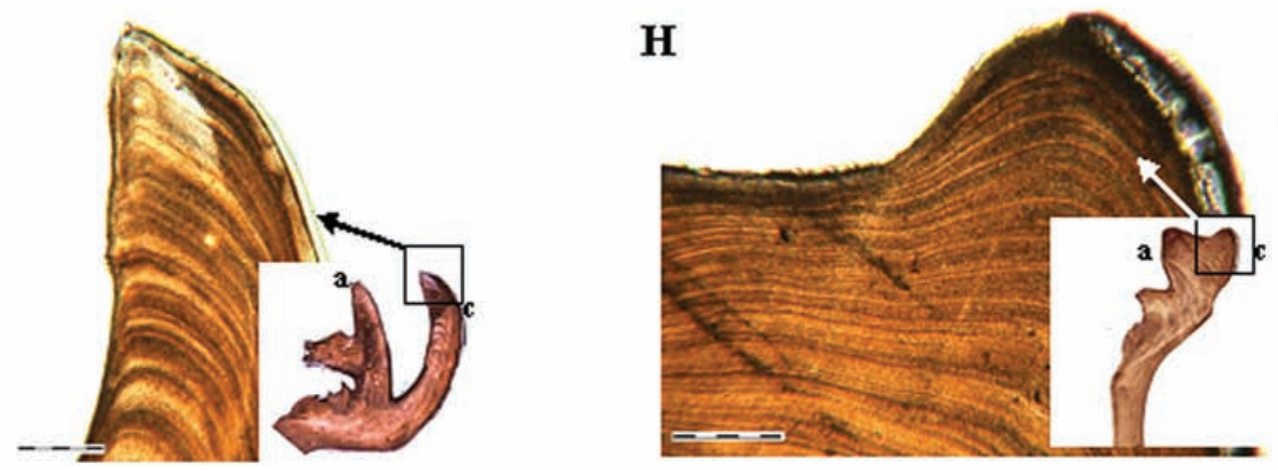

Figure 2. Appearance of $(A)$ the side view to highlight the complex curvature around the umbonal region and (B) the complete right valve of Glossus humanus; scale bars $=I \mathrm{~cm}$. (C) Detail of the hinge area of $G$. humanus to show the direction of the five sections (D-H) taken through the (a) anterior and the (c) central cardinal teeth, used to investigate the optimum positions for the sections which appear in figures (D $H)$. (D - H) Photomicrographs of the acetate peel replicas showing at high power a portion of a selected cardinal tooth, the position of the photomicrograph is indicated by the black box inset on low power image. ( $D$ and $E$ ) The anterior and the central cardinal teeth are connected, and the growth lines are indistinct; $(\mathrm{F}$ and $\mathrm{G})$ the cardinal and central teeth are separate allowing a clear image of the growth lines in the cardinal tooth and $(\mathrm{H})$ both teeth have coalesced, and the growth lines are unclear. Scale bars are $500 \mu \mathrm{m}$.

the Isle of Man (Butler, 2009). Analysis of shell morphometrics therefore guides the selection of optimal shell valves with potentially the greatest longevity and minimal degradation of the internal growth record increasing the probability of finding crossmatches between contemporary shell material of unknown antiquity.

\section{Shell sectioning}

The umbonal region of $G$. humanus shells is spirally enrolled (Figure 2A and B) and directed anteriorly (Owen, 1953), which hinders the sectioning and examination of the growth records in the ventral margin, as is the optimal line of section for $A$. islandica (Richardson, 2001), since the resulting record would miss a 
significant number of the earliest growth increments. However, records derived from the central cardinal tooth could negate such an issue. To establish the most suitable line for sectioning, a series of sequential sections were taken through the umbonal region. The shell valve was cut using a diamond-tipped grinding saw perpendicular to the line of maximum growth separating the ventral margin from the umbone. The umbone section was embedded in epoxy resin (see Butler et al., 2009) for further sectioning.

A series of seven sections (Figure 2C-H) were sequentially ground parallel to the axis of maximum growth through the cardinal teeth of one shell valve (gh0005). For each section, the embedded shell surface was ground using progressively finer grades of carborundum paper (grades 120-4000) and polished on a rotating polishing table using diamond paste (see Scourse et al., 2006). The polished surface was etched for $90 \mathrm{~s}$ in $0.1 \mathrm{M} \mathrm{HCl}$ solution, bathed in distilled water, and left to air dry under a fume hood. Acetate peel replicas were taken of the etched surface using the procedure described by Richardson (2001). Digital photomosaics were constructed from individual photomicrographs taken serially across each acetate peel replica using a light-transmitting microscope under $2.5 \times$, $4 \times$ and $10 \times$ magnification to enable the growth record to be digitally measured and recorded.

Shells were selected for sectioning based on the condition of the shell (minimal bioerosion, periostracum preserved and ligament present). A total of 43 of the largest ( $>65 \mathrm{~mm}$ in shell length) specimens of optimal condition were sectioned through the apex of the central cardinal tooth, and acetate peel replicas were prepared using the methods described above. Growth increment widths were measured digitally using the imaging system analySIS (version 3.2 produced by Soft Imaging System; see Butler et al., 2009).

\section{X-ray diffraction analysis}

In order for the oxygen isotope ratios in the shell carbonate to be used as a geochemical proxy for seawater temperature, it is necessary to determine which crystalline polymorph of $\mathrm{CaCO}_{3}$ is present (calcite, aragonite or a mixture of the two) in the shell. A 2.5-cm section of shell material, cut from the ventral margin of a single valve and including portions of both inner and outer shell layers, was submitted to Dr E. Harper at the University Cambridge, United Kingdom, for X-ray diffraction (XRD) analysis.

\section{Stable isotope $\left(\delta^{18} O\right)$ analysis}

The calcium carbonate phase of most bivalve molluscs forms in oxygen isotopic equilibrium with the ambient seawater (for exceptions, see, for example, Hallmann et al., 2008). Seasonal changes in temperature are reflected as varying $\delta^{18} \mathrm{O}$ composition in the $\mathrm{CaCO}_{3}$ phase of the shell. The seasonal variations in $\delta^{18} \mathrm{O}$ have been used to assess the periodicity of internal growth line formation in A. islandica valves (Witbaard et al., 1994).

In total, 28 samples were sequentially micro-milled (drilled) from two individual growth increments in three independent dead-collected G. humanus valves from the Sound of Mull. In order to obtain sufficient sampling resolution to depict seasonality, the widest growth increments, from the earliest years of ontogeny, in the outer shell layer of the ventral margin, were sampled. Samples were drilled using a New Wave Merchanteck ${ }^{\mathrm{TM}}$ micro-mill using a tungsten carbide dental bur (drill bit). Samples were analysed using a Finnigan MAT Delta Plus XL mass spectrometer in continuous flow mode connected to a Gas Bench with a CombiPAL autosampler. Reference standards (NBS-18, NBS19 and LSVEC) were used for isotopic corrections and to assign the data to the appropriate isotopic scale. At least one reference standard was used for every five samples. The combined uncertainty (internal precision and average correction factor for non-linearity) for $\delta^{18} \mathrm{O}$ is $\pm 0.09 \%$ (Vienna Pee Dee Belemnite (VPDB))

\section{Shell dating}

Two independent methods of dating were applied to the sectioned G. humanus shells in an attempt to provide an assessment of the temporal distribution of the shell collections. Cross dating is a commonly used tool in dendrochronological and sclerochronological studies for the construction of statistically robust chronologies. Cross dating enables the absolute dating of dead-collected shells by comparing their growth patterns with those from specimens with known dates of death. Cross dating techniques have been used to form statistically robust absolutely dated A. islandica and Glycymeris glycymeris sclerochronologies spanning decades to centuries (Brocas et al., 2013; Butler et al., 2013; Reynolds et al., 2013). In addition to these single species studies, there is a growing body of evidence that individual species of marine bivalve molluscs share a common growth response to environmental forcing with other marine bivalve species (Witbaard et al., 2006) as well as otolith records from marine fish (Black, 2009) and terrestrial dendrochronological records (Black et al., 2012; Schöne and Fiebig, 2009).

Cross dating. As it has been demonstrated that growth increments can be formed in synchrony within and between populations of the same and different species (Butler et al., 2009; Witbaard et al., 2006), cross dating techniques were used to compare the growth increment width series between the deadcollected $G$. humanus and a previously published absolutely dated statistically robust G. glycymeris sclerochronology (containing 12 dead- and 10 live-collected G. glycymeris shells) constructed from shell material in the Tiree Passage (Reynolds et al., 2013).

The G. humanus shells were selected for sectioning based on the condition of the shell (minimal bioerosion, periostracum preserved and ligament present). A total of 43 of the largest (>65 $\mathrm{mm}$ in shell length) specimens in optimal condition were sectioned through the apex of the central cardinal tooth, and acetate peel replicas were prepared using the methods described above. Growth increment widths were measured digitally using the imaging system AnalySIS (version 3.2 produced by Soft Imaging System; see Butler et al., 2009). As all the G. humanus included in the cross dating were dead-collected, arbitrary years of death were initially assigned to the outermost growth increment, and the other increments were dated relative to the outermost increment. The incremental series were then cross dated using SHELLCORR run in MATLAB V13 (Butler et al., 2009; Scourse et al., 2006). We used statistical techniques commonly applied in the construction of $A$. islandica chronologies to remove ontogenetic trends, allowing for a direct comparison of the interannual growth variability between the shells (Butler et al., 2009; Scourse et al., 2006). Log transformation and flexible spline detrending were used to remove variance stabilization and correct for ontogenetic decrease of shell growth while preserving high-frequency variability in order to compare interannual growth variability (Butler et al., 2009). SHELLCORR outputs the running correlation coefficients (calculated over 7- to 45-year windows), as graphical displays allowing for the detection of lags and offsets between growth increment series; these plots allow for the detection of probable misidentified growth increments. A master sclerochronology was not constructed from the crossmatched $G$. humanus shells, as only a small number of the dead-collected shells statistically crossmatched. In order to define an absolute date, the crossmatched G. humanus shells from the Sound of Mull site were cross dated against the absolutely dated Tiree Passage $G$. glycymeris sclerochronology. The G. humanus and $G$. 
Table 2. Un-calibrated radiocarbon ages and the positions at which the calcium carbonate samples were taken on the G. humanus valves: results from samples run at East Kilbride radiocarbon facility.

\begin{tabular}{|c|c|c|c|c|}
\hline Lab ID & Shell ID & Sample position & Site & ${ }^{14} \mathrm{C}$ age \\
\hline SUERC-234I9 & 00013 & Umbone & Site I & $4 I I \pm 35$ \\
\hline SUERC-23420 & 00003 & Ventral margin & Site I & $494 \pm 37$ \\
\hline SUERC-23424 & 00054 & Ventral margin & Site 3 & $555 \pm 37$ \\
\hline SUERC-2342I & 00051 & Umbone & Site 3 & $627 \pm 35$ \\
\hline SUERC-23422 & 00051 & Ventral margin & Site 3 & $562 \pm 37$ \\
\hline SUERC-23423 & 00024 & Ventral margin & Site 3 & $1203 \pm 37$ \\
\hline
\end{tabular}

glycymeris growth increment widths were cross-correlated using the standard cross dating techniques in SHELLCORR as described above.

AMS radiocarbon $\left({ }^{14} \mathrm{C}\right)$ sampling.. $\quad$ AMS ${ }^{14} \mathrm{C}$ dating has been utilized in previous sclerochronological studies to independently validate cross dating (Scourse et al., 2006) as well as to provide evidence of the periodicity of the growth line formation in $A$. islandica (Witbaard et al., 1994). A total of 10 shell subsamples were analysed by AMS (four at the Radiocarbon Laboratory of the University of Aarhus, Denmark, and six at the NERC Radiocarbon Facility East Kilbride, (NRCF-E), UK; see Table 2). Prior to sampling, the valves were cleaned and the periostracum removed. Subsamples were then drilled from the outer shell surface using a hand-held Dremmel drill. In addition to providing independent evidence of the temporal distribution of the species, the sampling positions were selected to provide independent evidence for two hypotheses: (1) cross dating provides a robust dating tool for the $G$. humanus shells and (2) the G. humanus growth increments are formed with annual periodicity. Single $\mathrm{CaCO}_{3}$ samples were drilled from shells that were found to statistically cross date either with each other or the G. glycymeris chronology. In addition, paired samples were taken from the ventral margin and the umbone region of three shells (00013, 00046 and 00051) to allow the periodicity of growth line formation to be assessed.

\section{Results}

\section{Sample collections and morphometrics}

In total, 67 single and four articulated G. humanus valves were dead-collected from 12 tows of a mechanical dredge from a site situated in the mouth of Loch Sunart in the Sound of Mull (site 1) and from two sites within Loch Sunart (sites 2 and 3) and (Table 1). However, during the subsequent extensive searches, carried out at each of the three sites by the NFSD team, only one live G. humanus valve was collected from Site 3.

The shells collected ranged in size from 41.2 to $88.4 \mathrm{~mm}$ in shell length with a mean of $68.24 \mathrm{~mm}(\sigma=10.79 \mathrm{~mm})$. Figure 3 shows that the percentage size class distribution of the shell lengths (black bars) and maximum shell height (grey bars) are normally distributed; however, there is a notable absence of the smaller size classes $(<40 \mathrm{~mm})$. The lack of smaller size classes is not thought to be a sampling bias caused by the mesh size of the dredge as specimens of $A$. islandica of $<40 \mathrm{~mm}$ in shell length were collected during the same tows (Reynolds, 2011).

\section{Sequential sectioning}

The sequential sectioning strategy revealed that the optimum line of section through a G. humanus shell valve is through the apex of the central cardinal tooth (Figure 2F). The photomicrographs of sections either side of the apex of the central cardinal tooth (Figure $2 \mathrm{D}, \mathrm{E}, \mathrm{G}$ and $\mathrm{H}$ ) contain growth lines with widths that vary widely across the section, which may lead to inaccuracies in the increment width measurements, as well as the central and anterior cardinal teeth being merged, which complicates identification of the axis of maximum growth. In Figure 2F, however, the widths of the growth increments are consistent across a large portion of the tooth; as such, the axis of maximum growth covers the broadest portion of the section making accurate measurement easier and comparison between shells more consistent.

\section{Growth increment analysis}

The G. humanus growth increment series contain a large degree of variability. The mean maximum umbonal growth rate of the shells measured (c. $900 \mu \mathrm{m} / \mathrm{yr}$ ) occurs during the first 10 years (Figure 4a) before exponentially decreasing. From 40 years of age, the mean growth rate stabilizes at $c .100 \mu \mathrm{m} / \mathrm{yr}$. The degree of growth variability between individuals shows a similar exponential decline with increasing age (Figure 4b); the greatest variability of growth between individuals, ontogenetically aligned, is $600 \mu \mathrm{m}$ occurring during the first 10 years. After $c$. 30-40 years, variability is reduced to $c$. $50 \mu \mathrm{m}$. It is critical that a sclerochronological archive contains a high level of interannual variability throughout its lifetime in order to facilitate cross dating and climatological reconstructions. Figure 4c displays mean interannual variability of growth which follows a general negative exponential curve, with the highest degree of variability occurring during the first $10-15$ years before reducing to a stable level of c. $20 \mu \mathrm{m} / \mathrm{yr}$.

\section{$X R D$ analysis}

The XRD analysis of the powdered $\mathrm{CaCO}_{3}$ portion, cut from the ventral margin of one dead-collected $G$. humanus valve, identifies the sample as $100 \%$ aragonite, confirming that the standard aragonitic palaeotemperature equations (e.g. Grossman and Ku, 1986) can be used to convert stable oxygen isotope ratios to seawater temperatures.

\section{Oxygen stable isotopes}

The mean $\delta^{18} \mathrm{O}$ range across the six micro-milled growth increments was $1.12 \%$, equivalent to a mean seasonal temperature range of $c .4 .6^{\circ} \mathrm{C}$. The interannual variability was removed by normalizing the data to the overall mean and standard deviation; this was done to allow the direct comparison of seasonal variability across the shells irrespective of mean annual conditions. The resulting normalized $\delta^{18} \mathrm{O}$ concentrations were then converted to water temperatures using the Grossman and $\mathrm{Ku}$ (1986) palaeotemperature equation. However, a small modification of their equation was required because they report oxygen isotope values of seawater $\left(\delta^{18} \mathrm{O}_{\text {water }}\right)$ in Standard Mean Ocean Water (SMOW) $-0.27 \%$ (see footnote in Dettman et al., 1999). The corrected function is as follows (Eq. (1)):

$$
\begin{aligned}
T\left({ }^{\circ} \mathrm{C}\right)= & 20.60-4.34 \times\left(\delta^{18} O_{\text {aragonite }}-\right. \\
& \left.\left(\delta^{18} O_{\text {water }}-0.27\right)\right)
\end{aligned}
$$




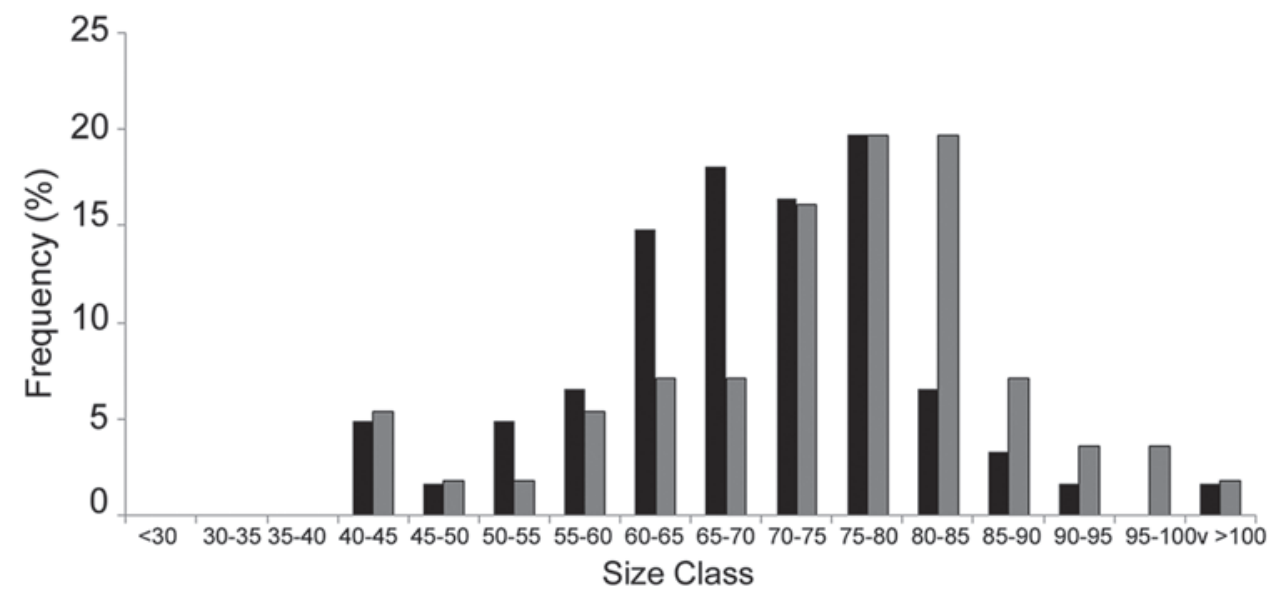

Figure 3. Percentage size frequency distributions of the shell length (dark grey) and maximum shell heights (light grey) of the G. humanus shells collected by mechanical dredge from Loch Sunart in 2006. Sample size $N=71$.

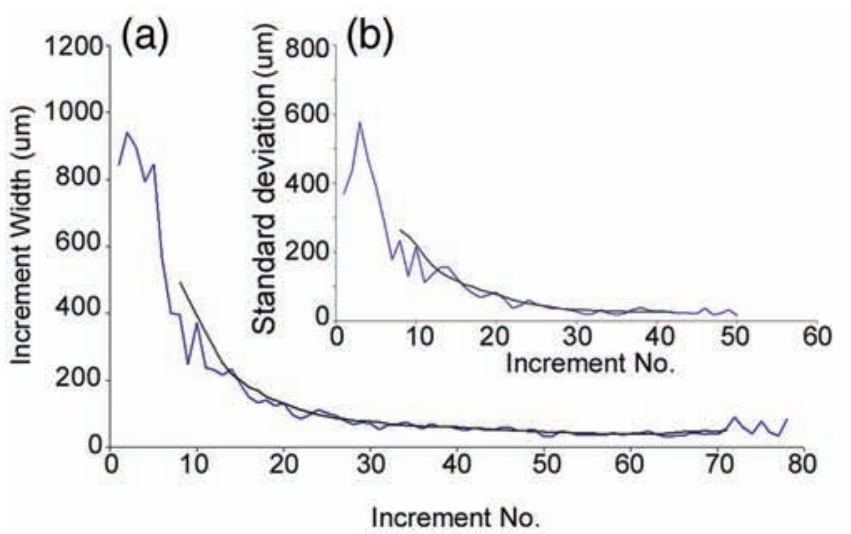

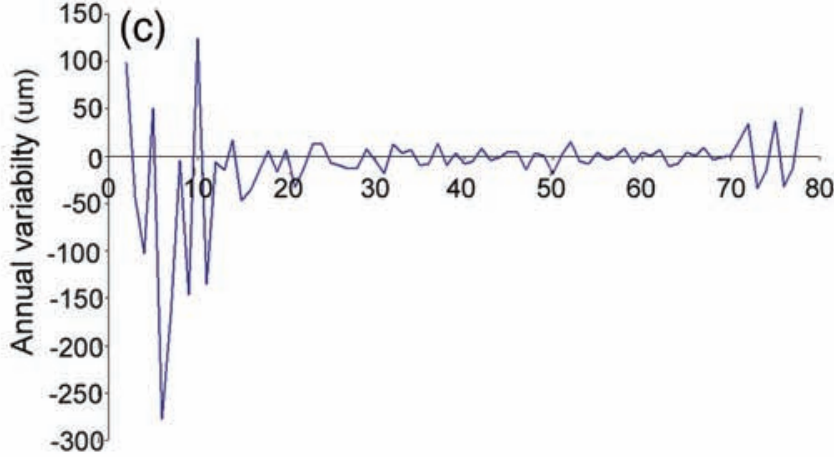

Increment No.

Figure 4. (a) Average growth increment widths (blue line) from 20 randomly selected Glossus humanus specimens, fitted with a 15 -year moving average (black line). (b) Standard deviation of increment widths across the 20 measured shells (blue line) fitted with 15-year moving average (black line). (c) Mean interannual variability calculated by means of first differencing.

where $\delta^{18} \mathrm{O}_{\text {aragonite }}$ denotes the $\delta^{18} \mathrm{O}$ values derived from biogenic aragonite and $\delta^{18} O_{\text {water }}$ denotes the $\delta^{18} \mathrm{O}$ value of the ambient water. The Cage and Austin (2010), mixing line equation (Eq. (2)) for Loch Sunart was used to calculate a representative value for $\delta^{18} O_{\text {water }}$ based on mean salinity within the Tiree Passage:

$$
\delta^{18} O_{\text {water }}=0.18 * \text { salinity }(\mathrm{PSU})-6.00
$$

where salinity is the ambient water salinity in practical salinity units (PSU). The $\delta^{18} \mathrm{O}$ derived mean bottom water temperatures $\left(\mathrm{T}_{\left(\delta^{18} \mathrm{O}\right)}\right.$; Figure 5) show similar trends across all six growth increments analysed. The $\mathrm{T}_{\left(\delta^{18} \mathrm{O}\right)}$ show a bimodal seasonality with a warming trend in the early season growth with a reduction in temperatures/slow down in the warming trend during the middle of the growth increment. Peak temperatures are reached during a second phase of warming that occurs just prior to the formation of the growth check. The $\mathrm{T}_{\left(\delta^{18} \mathrm{O}\right)}$ fall within the range of the mean seasonal SST series recorded in the Tiree Passage (Inall et al., 2009).

\section{Shell dating}

Cross dating. Detrended growth increment series from the 30 G. humanus shells that contained more than 25 measured growth increments were correlated against each other and $G$. glycymeris chronology indices. Significant $(p<0.01)$ positive correlations were identified between three $G$. humanus from the Sound of Mull site (mean $R=0.307$; mean series overlap $=32$ years) and four from Site 3 and (mean $R=0.412$; mean series overlap $=29$ years; Figure 6 ). The number of shells crossmatched at the Sound of Mull and site 3 is insufficient (three and four, respectively) to construct a robust master sclerochronology. Significant $(p<0.01)$ positive correlations were also identified between the three specimens crossmatched from the Sound of Mull site and the G. glycymeris shells contained in the Tiree Passage sclerochronology. The interspecies cross dating of the Sound of Mull and Tiree Passage shells allows the absolute dating of the three dead-collected $G$. humanus shells from the Sound of Mull. These results indicate that the three cross dated shells from the Sound of Mull lived from the early 1900s through to 1967.

AMS radiocarbon $\left({ }^{14} \mathrm{C}\right)$ dating. Of the $10{ }^{14} \mathrm{C}$ determinations, 9 furnished conventional ${ }^{14} \mathrm{C}$ dates predating the bomb pulse (AD 1950), while one was returned with a modern date (post $A D$ 1950). The nine conventional ${ }^{14} \mathrm{C}$ dates were calibrated using the Marine09 radiocarbon calibration curve (Reimer et al., 2009) using the OxCal online software (Bronk Ramsey, 1994, 2001). The modern sample AAR11601, taken from the ventral margin of shell 00013, had a radiocarbon value of $126 \pm 0.47 \% \mathrm{MC}$ (percent modern carbon). This sample was calibrated using a composite bomb pulse curve (Figure 7; Scourse et al., 2012) to AD 


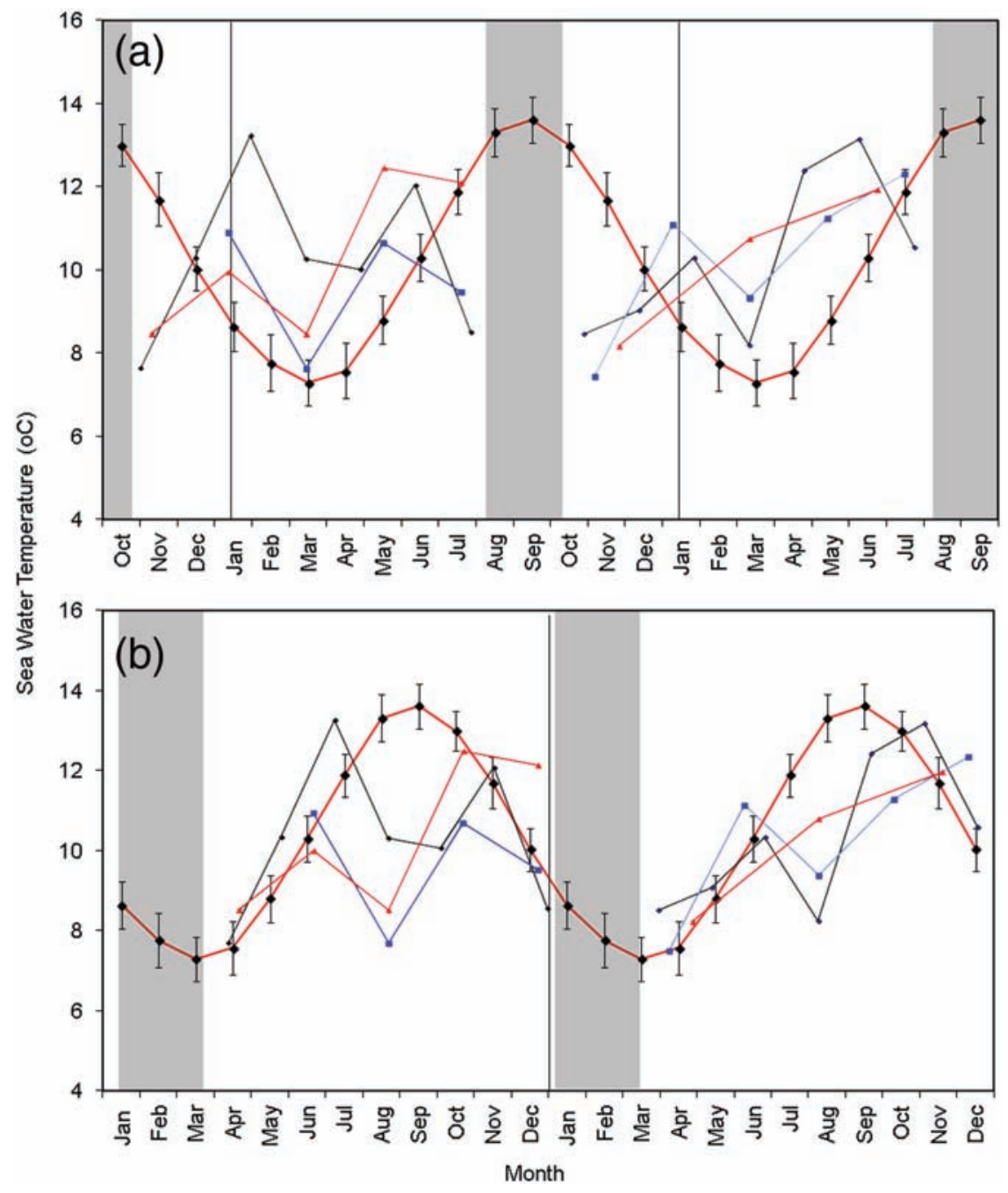

Figure 5. Normalized $\delta^{18} \mathrm{O}$-derived reconstructed BWTs, from high-resolution sampling of the biogenic aragonite through two successive increments within three independent G. humanus shells, plotted against mean monthly SST data from the Tiree Passage (red line and black diamond's). These plots represent the two hypotheses regarding the timing of growth line formation, with the growth line forming in the winter and in the summer in plots (a) and (b), respectively.

BWT: bottom seawater temperature; SST: sea surface temperature.

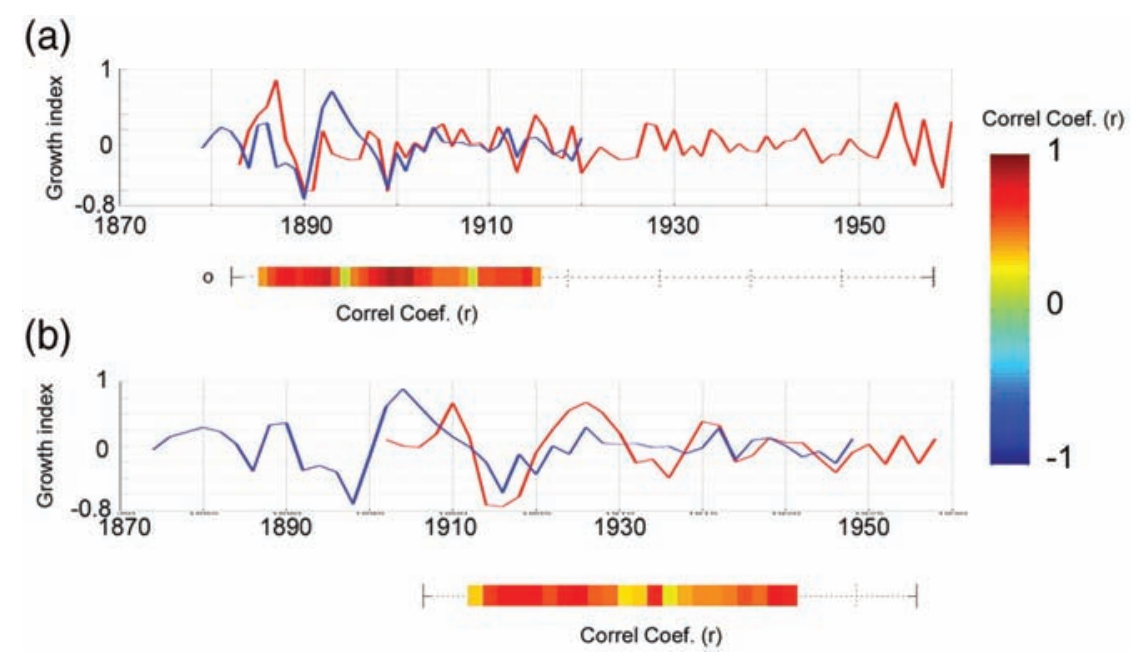

Figure 6. Crossmatching outputs from SHELLCORR comparing the detrended growth increment width series of shells (a) 00013 and $0005 \mathrm{I}$ and (b) $0005 \mathrm{I}$ and 00024 with corresponding Pearson correlation coefficients shown in a moving window of I5 years. Correlations are displayed on a colour gradient scale with red indicating a strong positive correlation.

1967 ( \pm 10 years sclerochronological error). The raw and calibrated ${ }^{14} \mathrm{C}$ results (Table 3 and Figure 8 , respectively) demonstrate that shells from Site 3 are significantly older than the shells from the Sound of Mull, with probability distributions 


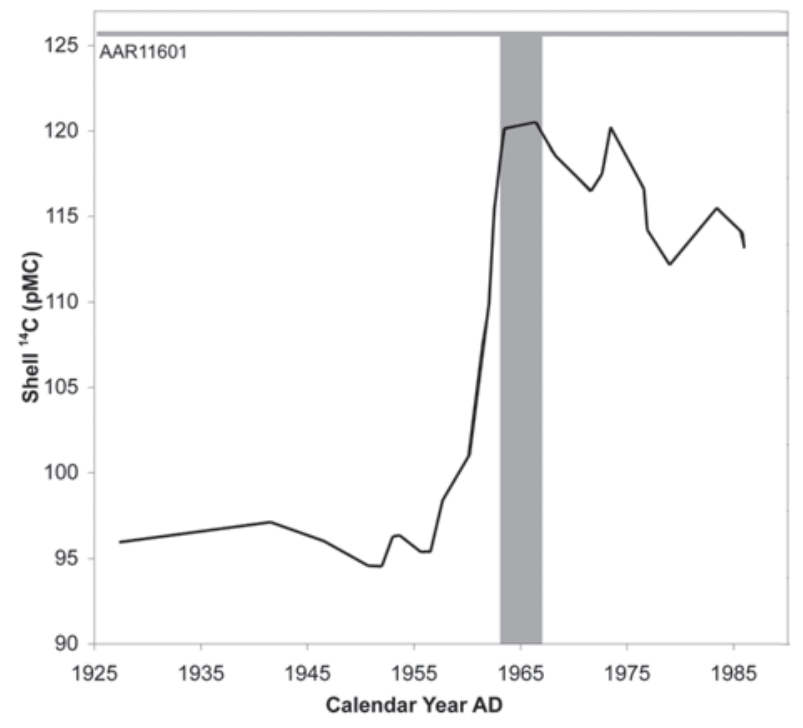

Figure 7. Regional ${ }^{14} \mathrm{C}$ bomb pulse curve (percent modern carbon; black line) derived from Arctica islandica shells from the North Sea (figure modified from Scourse et al., 20I2). The shaded grey lines denote 126\%MC and the basis for calibration of Glossus humanus AARII60I to c.AD 1967.

Table 3. Un-calibrated radiocarbon ages and the positions at which the calcium carbonate samples were taken on the G. humanus valves: results from samples run at the Aarhus radiocarbon facility.

\begin{tabular}{llllr}
\hline Lab ID & Shell ID & Sample position & Site & \multicolumn{1}{c}{${ }^{14}$ C age } \\
\hline ARII602 & 00015 & Umbone & Site I & $389 \pm 33$ \\
ARII60I & 00013 & Ventral margin & Site I & $-1865 \pm 30$ \\
ARII603 & 00046 & Ventral margin & Site 3 & $657 \pm 42$ \\
ARII604 & 00046 & Umbone & Site 3 & $555 \pm 31$ \\
\hline
\end{tabular}

spanning c. AD 1100-1800 for site 3 and c. 1800-1990 for site 1 (Figure 8).

\section{Discussion}

Moderate numbers of fossil G. humanus were collected from the two sites in the main basin of Loch Sunart as well as a third site situated at the mouth of Loch Sunart in the Sound of Mull. However, despite the relatively large numbers of fossil specimens, live $G$. humanus were all but absent, with only a single specimen being collected by the NFSD team. In order to build an absolutely dated chronology, it is critical to collect a moderate number of live specimens in order to be able to assign absolute calendar years to each of the growth increments. The lack of livecollected material in this case would preclude the construction of such a series.

Analysis of the morphometrics revealed that the majority of dead-collected and the single live-collected $G$. humanus are of the larger size classes. The deficiency of small size classes in the collection is not thought to be a sampling bias due to mesh size on the dredge as other small bivalves (including $A$. islandica) were collected in the same tow.

Following the determination that the optimal line of sectioning the G. humanus shell was through the apex of the central cardinal tooth, the digital photomicrographs taken of the acetate peel replicas allowed the internal growth increment series to be visualized and digitally measured from both the live- and dead-collected shell material. The maximum longevity recorded in the shells collected in this study is 78 years, with a mean longevity of 45 years. This range in longevity, although substantially shorter than that of A. islandica (>500 years maximum longevity; Butler et al., 2013), would nevertheless enable statistically significant periods of overlap to be established between growth increment series facilitating the construction of statistically robust sclerochronologies.

\section{$X R D$ and isotope analysis}

As the XRD analysis determined that the G. humanus shell portion was $100 \%$ aragonite, it is possible to use the conventional palaeotemperature equation to convert the $\delta^{18} \mathrm{O}$ concentrations into absolute seawater temperatures, in this case, bottom water temperatures. The $\mathrm{T}_{\left(\delta^{18} \mathrm{O}\right)}$ show two periods of warming (Figure 5), followed by cooling or no warming phases. The $\mathrm{T}_{\left(\delta^{18} \mathrm{O}\right)}$ profiles decouple from the observed regional mean seasonal SSTs, indicating a seasonally stratified water-column. These data therefore suggest that the growth increments are formed with an annual period. However, with regard to the timing of growth line (check) formation, caused by either a complete cessation or slowdown in growth, there are two possible interpretations of the $\mathrm{T}_{\left(\delta^{18} \mathrm{O}\right)}$ : (1) the growth check is formed during the period of December through to March/April, with the growth period being from May through to November/December, the decline in summer bottom water temperatures is a direct result of the thermocline development which is followed by a peak warming as the thermocline breaks down in the late summer/autumn; (2) the growth check forms from July to September/October, with the breakdown in the thermocline warming bottom waters and initiating growth, which continues through the winter and halts as the water stratifies in late spring/early summer. Comparison of the $\mathrm{T}_{\left(\delta^{18} \mathrm{O}\right)}$ with the average seasonal SSTs recorded from the Tiree Passage oceanographic mooring (Inall et al., 2009) - average seasonal SSTs were used as no direct observational data were available for the reconstructed period - indicates that the $\mathrm{T}_{\left(\delta^{1 \mathrm{O}} \mathrm{O}\right)}$ do not fall below the mean seasonal minimum SST, as might be expected for bottom water temperatures during the winter period. Similarly, the peak $\mathrm{T}_{\left(\delta^{18} \mathrm{O}\right)}$ is close to the peak mean summer SST and occurs just prior to the formation of the growth check. We therefore interpret the G. humanus growth check as a winter check (December to April), with peak growth during the spring and summer seasons.

\section{Shell dating}

The ability to use G. humanus as a sclerochronological archive is dependent on there being a sufficient quantity of fossil shell material available with a reasonably extensive temporal distribution. The significant positive correlation coefficients identified between the $G$. humanus growth increment series derived from shells from sites 1 and 3, supported by radiocarbon dating, indicate that the fossil shells, in the two sites, are coeval. However, despite crossmatches being identified, an insufficient number of shells could be crossmatched to form a robust sclerochronology. Typically, robust master sclerochronologies, defined by the expressed population signal exceeding 0.85 (Wigley et al., 1984) have contained a minimum of c. 8-10 shells during any given period (Brocas et al., 2013; Butler et al., 2009; Reynolds et al., 2013). The difficulty of obtaining sufficient shells for crossmatching would severely hinder the use of G. humanus in the construction of further master sclerochronologies. The crossmatching completed on the G. humanus, however, does not provide the timing of the existence of the apparent populations. The cross dating between the Sound of Mull G. humanus shell series and the G. glycymeris master sclerochronology from the Tiree Passage was a novel attempt to date the G. humanus shells 

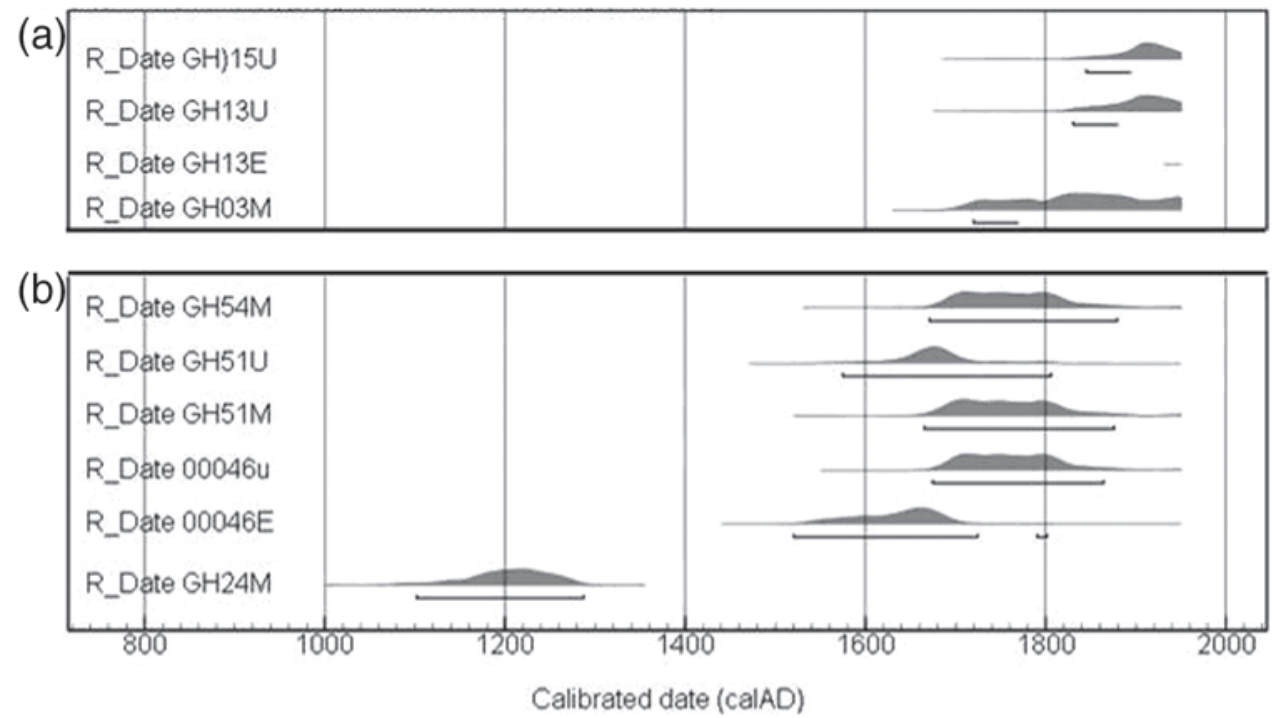

Figure 8. ${ }^{14} \mathrm{C}$ calibration plot for shell samples taken from the crossmatched shells from (a) site I and (b) site 3, respectively. The shaded grey areas represent probability histograms illustrating the most likely date determinations. Samples calibrated using the Marine 09 , marine ${ }^{14} \mathrm{C}$ calibration curve; R_Date GHI3E was dated post-bomb and as such was calibrated using the marine bomb pulse curves to AD 1967 (Figure 7).

relative to an existing absolutely dated sclerochronology from another species. The significant positive correlations (ranging from $R=0.2-0.7$ calculated over a 21-year running window) identified between the growth series of the two species indicates that the Sound of Mull G. humanus may cross date with the $G$. glycymeris chronology, thus enabling the precise timing of settlement and death of the Sound of Mull G. humanus specimens to be derived. These results suggest that distinct species from the same hydrographic setting can show similar growth responses to their common environmental drivers, supporting the hypothesis that it is possible to construct a multispecies sclerochronology. This conjecture will be addressed in a subsequent manuscript (Reynolds et al., in press).

The radiocarbon dating applied to both site 1 and site $3 G$. humanus shells provides independent support for the inter- and intraspecies cross dating, as well as a broad indication of the temporal distribution of the populations. There is close agreement between the ${ }^{14} \mathrm{C}$ determinations from all of the shells at each site, supporting the hypothesis that the fossil shells crossmatched from each site are contemporary. Furthermore, the ${ }^{14} \mathrm{C}$ determination from the longest-lived dead-collected $G$. humanus (00013), from the Sound of Mull, was calibrated using a composite ${ }^{14} \mathrm{C}$ bomb pulse curve compiled by Scourse et al. (2012). The high modern ${ }^{14} \mathrm{C}$ determination from shell 00013, in comparison with the published curves, allows for accurate calibration of the ${ }^{14} \mathrm{C}$ determination and dates the sample to the years of peak ${ }^{14} \mathrm{C}$ concentrations within the marine environments (AD 1965-1967 \pm 10 years error based on integration of multiple growth increments within the sample). The precise nature of the dating of this specimen provides a strict test of the dating estimate provided by the cross dating between the Sound of Mull G. humanus and the Tiree Passage G. glycymeris master sclerochronology.

The calibrated ${ }^{14} \mathrm{C}$ determination from shell 00024 , that was initially crossmatched with the three shells from site 3 , is significantly older than the other dated material from site 3 (00024 calibrated date $\sim 13$ th century AD), indicating that shell 00024 was spuriously crossmatched. This highlights the need to independently validate all crossmatching by means of ${ }^{14} \mathrm{C}$ dating.

The ${ }^{14} \mathrm{C}$ determinations from each of the three shells (00013, 00046 and 00051 ) from which two subsamples were taken revealed that the interval between the ${ }^{14} \mathrm{C}$ dates on all three shells, within errors (c. \pm 100 years), is consistent with the number of growth increments counted in each of the photomicrographs. These data in addition to the $\delta^{18} \mathrm{O}$ data provide strong evidence that the growth increments in $G$. humanus are formed on an annual basis.

\section{Conclusion}

The results presented here show that it is possible to section $G$. humanus shells to enable the longevity and growth history to be recorded in full. The oxygen isotope and ${ }^{14} \mathrm{C}$ data indicate that the internal growth increments in the shell valves of G. humanus are formed annually, with the growth check most likely forming during the winter months. Analysis of detrended growth increment series shows that the interannual variability in growth is likely to be synchronous within the studied populations. Although the maximum longevity of $G$. humanus is significantly shorter than that of A. islandica, it would be sufficient to allow cross dating and the construction of robust sclerochronologies given enough available material. Though these results present technical evidence that $G$. humanus could be used as a robust sclerochronological archive, it is unlikely to do so due the scarcity of extant populations. The ${ }^{14} \mathrm{C}$ and cross dating estimate of shell antiquity suggests fossil G. humanus specimens are present in Loch Sunart and the surrounding waters that may facilitate the construction of master sclerochronologies. The ${ }^{14} \mathrm{C}$ dating indicates that $G$. humanus specimens can remain in optimal condition in the environment for over 700 years. However, the fragile nature of the shell may impact the numbers of older specimens preserved, so extending $G$. humanus records backwards through time could be problematic. Nevertheless, these data do highlight the potential of using $G$. humanus growth records to complement sclerochronologies based on other species, for example, G. glycymeris, as these data demonstrate that interspecies crossmatching is feasible. This latter finding indicates common forcings influencing populations of different species within specific regions.

\section{Acknowledgements}

The authors would like to thank Professor John Taylor of the Natural History Museum (London) and Dr Ellen Strong of the US National Museum of Natural History (Washington, DC) for donating collection data and Dr Elizabeth Harper of the University of Cambridge, the officers and crew of the RV Prince Madog and the entire NFSD team involved with the diving collection. We 
thank Ian Harris for the use of the cross dating program SHELLCORR. This paper is a contribution to the Climate Change Consortium for Wales. We also acknowledge the constructive advice of the reviewers.

\section{Funding}

This research was supported with financial and or practical help by the Natural Environment Research Council (NERC) Radiocarbon Facility (NRCF; Allocation number 1330.1008), EU Millennium Project (European Climate of the Last Millennium; Project number 017008) and QRA New Research Workers Award, NERC Facility for Scientific Diving (Grant No. NFSD/09/01). This work has been supported by the NERC-funded ULTRA project (Grant No. NE/H023356/1)

\section{References}

Ambrose WG, Carroll ML, Greenacre M et al. (2006) Variation in Serripes groenlandicus (Bivalvia) growth in a Norwegian high-Arctic fjord: Evidence for local- and large-scale climatic forcing. Global Change Biology 12: $1595-1607$.

Balson P (1990) The 'Trimley Sands': A former marine Neogene deposit from eastern England. Tertiary Research 11: 145-158.

Black BA (2009) Climate-driven synchrony across tree, bivalve, and rockfish growth-increment chronologies of the northeast Pacific. Marine Ecology Progress Series 378: 37-46.

Black BA, Copenheaver CA, Frank DC et al. (2012) Multi-proxy reconstructions of northeastern Pacific sea surface temperature data from trees and Pacific geoduck. Palaeogeography, Palaeoclimatology, Palaeoecology 278: 40-47.

Brocas WM, Reynolds DJ, Butler PG et al. (2013) The dog cockle, Glycymeris glycymeris (L.), a new annually-resolved sclerochronological archive for the Irish Sea. Palaeogeography, Palaeoclimatology, Palaeoecology 373: 133-140.

Bronk Ramsey C (1994) Analysis of chronological information and radiocarbon calibration: The Program OxCal. Archaeological Computing Newsletter 41: 11-16.

Bronk Ramsey C (2001) Development of the radiocarbon calibration program OxCal. Radiocarbon 43(2A): 355-363.

Butler PG (2009) Establishing the Arctica islandica archive. Unpublished PhD Thesis, Bangor University, Gwynedd.

Butler PG, Richardson CA, Scourse JD et al. (2010) Temperature and stratification in the Irish Sea: Analysis of a 489-year marine master chronology derived from growth increments in the shell of the clam Arctica islandica. Quaternary Science Reviews 29: 1614-1632.

Butler PG, Scourse JD, Richardson CA et al. (2009) Continuous marine radiocarbon reservoir calibration and the ${ }^{13} \mathrm{C}$ Suess effect in the Irish Sea: Results from the first absolutely dated multi-centennial shellbased marine master chronology. Earth and Planetary Science Letters 279: 230-241.

Butler PG, Wanamaker AD Jr, Scourse JD et al. (2013) Variability of marine climate on the North Icelandic Shelf in a 1,357-year crossdated Arctica islandica chronology. Palaeoceanography, Palaeoclimatology, Palaeoecology 373: 141-151.

Cage AG and Austin WEN (2010) Marine climate variability during the last millennium: The Loch Sunart record, Scotland, UK. Quaternary Science Reviews 29: 1633-1647.

Dahlgren TG, Weidberg JR and Halanych KM (2000) Phylogeography of the ocean quahog (Arctica islandica): Influences of palaeoclimate on genetic diversity and species range. Marine Biology 37: 487-495.

Dettman DL, Reische AK and Lohmann KC (1999) Controls on the stable isotope composition of seasonal growth bands in aragonitic fresh-water bivalves (unionidae). Geochimica et Cosmochimica Acta 63(7-8): 1049-1057.

Grossman EL and Ku TL (1986) Oxygen and carbon isotope fractionation in biogenic aragonite: Temperature effects. Chemical Geology 59: 59-74.

Hallmann N, Schöne BR, Strom A et al. (2008) An intractable climate archive - Sclerochronological and shell oxygen isotope analyses of the Pacific geoduck, Panopea abrupta (bivalve mollusk) from Protection Island (Washington State, USA). Palaeogeography, Palaeoclimatology, Palaeoecology 269: 115-126.

Inall M, Gillibrand P, Griffiths C et al. (2009) On the oceanographic variability of the North-West European Shelf to the West of Scotland. Journal of Marine Systems 77: 210-226.
Jones D (1980) Annual cycle of shell growth increment formation in two contintental shell bivalves and palaeoecological significance. Paleoecology 6(3): 331-340.

Jones DS (1981) Annual growth increments in shells of Spissula solidissima record marine temperature variability. Science 211: 165-167.

Marchitto TM, Jones GA, Goodfriend GA et al. (2000) Precise temporal correlation of Holocene mollusc shells using sclerochronology. Quaternary Research 53(3): 236-246.

Nicol D (1951) Recent species of the Cyrenoid Pelecypod Glossus. Journal of the Washington Academy of Sciences 41(4): 142-146.

Owen G (1953) On the biology of Glossus humanus (L.) (Isocardia Cor Lam). Journal of the Marine Biological Association of the United Kingdom 31(1): 85-106.

Reimer PJ, Baillie MGL, Bard E et al. (2009) IntCal09 and Marine09 radiocarbon age calibration curves, 0-50,000 years cal BP. Radiocarbon 51(4): 1111-1150.

Reynolds DJ (2011) Establishing multi-bivalve species sclerochronology. PhD Thesis, Bangor University, Gwynedd.

Reynolds DJ, Butler PG, Scourse JD et al. (2013) A multiproxy reconstruction of Hebridean Shelf Sea spring sea surface temperatures from 1805-2010. Palaeoceanography, Palaeoclimatology, Palaeoecology 386: 275-285. DOI: 10.1016/j.palaeo.2013.05.029.

Rhoads DC and Lutz RA (eds) (1980) Skeletal Growth of Aquatic Organisms. New York: Plenum Press.

Richardson CA (2001) Molluscs as archives of environmental change. Oceanography and Marine Biology: Annual Review 39: 103-164.

Rosenberg GD and Runcorn SK (eds) (1975) Growth Rhythms and the History of the Earth's Rotation. London: Wiley.

Schöne BR and Fiebig J (2009) Seasonality in the North Sea during the Allerød and Late Medieval Climate Optimum using bivalve sclerochronology. International Journal of Earth Sciences 98: 83-98.

Schöne BR, Dunca E, Mutvei H et al. (2004) A 217-year record of summer air temperature reconstructed from freshwater pearl mussels (M. margarifitera, Sweden). Quaternary Science Reviews 23: 1803-18167.

Schöne BR, Fiebig J, Pfeiffer M et al. (2005) Climate records from a bivalve Methuselah (Arctica islandica, Mollusca; Iceland). Palaeoceanography, Palaeoclimatology, Palaeoecology 228: 130-148.

Schöne BR, Oschmann W, Rossler J et al. (2003) North Atlantic Oscillation dynamics recorded in shells of a long-lived bivalve mollusk. Geology 31: 1037-1040.

Scourse JD, Richardson CA, Forsythe G et al. (2006) First cross-matched floating chronology from the marine fossil record: Data from growth lines of the long-lived bivalve mollusc Arctica islandica. The Holocene 16(7): 965-972.

Scourse JD, Wanamaker AD Jr, Weidman C et al. (2012) The marine radiocarbon bomb-pulse across the temperate North Atlantic: $\Delta^{14} \mathrm{C}$ inventories from Arctica islandica growth increments. Radiocarbon 54(2): 165-186.

Stott KJ, Austin WEN, Sayer MDJ et al. (2010) The potential of Arctica islandica growth records to reconstruct coastal climate in north west Scotland, UK. Quaternary Science Reviews 29: 1602-1613.

Strom A, Francis RC, Mantua NJ et al. (2004) North Pacific climate recorded in growth rings of geoduck clams: A new tool for paleonvironmental reconstruction. Geophysical Research Letters 31: L06206. DOI: 10.1029/2004GL019440.

Thompson I, Jones DS and Dreibelbis D (1980) Annual internal growth banding and life history of the ocean quahog Arctica islandica (Mollusca: Bivlavia). Marine Biology 57: 25-37.

Wanamaker AD Jr, Butler PG, Scourse JD et al. (2012) Surface changes in the North Atlantic meridional overturning circulation during the last millennium. Nature Communications 3: 899. DOI: 10.1038/ncomms1901.

Wanamaker AD Jr, Heinemeier J, Scourse JD et al. (2008a) Very long-lived mollusks confirm 17th century ad tephra-based radiocarbon reservoir ages for North Icelandic Shelf waters. Radiocarbon 50(3): 399-412.

Wanamaker AD Jr, Kreutz KJ, Schöne BR et al. (2008b) Coupled North Atlantic slope water forcing on Gulf of Maine temperatures over the past millennium. Climate Dynamics 31: 183-194.

Wigley TML, Briffa K and Jones P (1984) On the average value of correlated time series, with applications in dendrochronology and hydro-meteorology. American Meteorological Society 23(2): 201-213.

Witbaard R, Duineveld GCA, Amaro T et al. (2006) Growth trends in three bivalve species indicate climate forcing on the benthic ecosystem in the southeastern North Sea. Climate Research 30: 29-38.

Witbaard R, Jansma E and Klaassen US (2003) Copepods link quahog growth to climate. Journal of Sea Research 50: 77-83.

Witbaard R, Jenness MI, Van Der Borg K et al. (1994) Verification of annual growth increments in Arctica islandica L. from the North Sea by means of oxygen and carbon isotopes. Journal of Sea Research 33: 91-101. 